\title{
Dendroecology in Asia
}

\author{
Achim Bräuning
}

Published online: 26 February 2013

(C) Springer-Verlag Berlin Heidelberg 2013

Though centered in a core area of human settlement and agricultural activity since prehistoric times, and despite tremendous forest losses due to overexploitation and conversion processes, Asia still hosts large areas and a wide variety of ecologically contrasting forests. While the monsoon regions of lowland southeast Asia are covered by tropical and subtropical evergreen humid or seasonal rainforests, the middle altitudinal belt of the Himalayas and western Chinese mountain regions are home of evergreen broadleaved forests. Around the margins of the Tibetan Plateau, high-altitude conifer forests form the highest treelines in the northern hemisphere. Finally, steppe forests with long-living juniper species form the transition to the central Asian grasslands and deserts, accompanied by riverine forests along streams that allow the growth of trees in a dry and tree-hostile environment. These contrasting environmental and climatic conditions offer plenty of opportunity to study relationships between trees and their adaptation to local climatic conditions. The papers of this special issue were presented during the Second International Asian Dendrochronological Conference held in Xi' an, China, during 20-23 August 2011, where more than 150 tree-ring researchers, mainly from Asian countries, participated. This collection of articles exemplifies quite well the variety and recent directions of dendroecological research in Asia.

Zhang et al. use a drought-sensitive network of juniper ring-width chronologies to analyse spatial and temporal patterns of moisture availability on the margin of the Asian Summer Monsoon realm on the northeastern Tibetan Plateau during the past 150 years and report about climatic

A. Bräuning $(\bowtie)$

Erlangen, Germany

e-mail: abraeuning@geographie.uni-erlangen.de teleconnections with the North Atlantic climate. Cai et al. study the drought history of the past 130 years at the arid margin of forests in the Yellow River catchment area, the eastern limit of the Asian Summer Monsoon influence. Both papers illustrate how tree-ring networks can enable the detection of shifts in current atmospheric circulation patterns.

Although the number of publications about reconstructions of various climatic parameters over Asia has literally boomed during the past years, there are still huge gaps of knowledge about climate-growth relationships in different climatological realms. One important issue is the lack of local climate stations in mountainous areas and their restriction to valley sites that may cause ambiguities and obstacles to calibrate climate-growth relationships of highelevation sites. On the other hand, the floristic composition of forest communities often stays relatively stable over hundreds of meters of elevation difference, raising the question whether there do exist differences in the growthlimiting climatic factors within one tree species along altitudinal gradients. The studies of Gao et al. and He et al. on different juniper species near the western distribution limit of tree growth on the Tibetan Plateau reveal a strong coherence of climate-growth relationships over altitudinal belts. On the other hand, these relationships may vary with time under different climatic conditions, which advise some caution regarding the inconsiderate application of present onto the past, a result confirmed by the study of Zhang et al. On the other hand, Liu et al. demonstrate that an extension of the growing season length due to temperature increase has not yet been accompanied by increasing growth of high-elevation Smith fir, giving credibility that temperature-limited sites on the southern Tibetan Plateau are still reliable indicators for temperature variations. This is of great interest, since phenology and tree height growth 
differ with altitude, as shown by one of the first phenological studies from the Tibetan Plateau by Wang et al. While the former works studied tree response to environmental changes on the landscape level, Yan et al. investigated changes of ecophysiological traits of conifer needles along an altitudinal gradient in the Changbai Mountains of northeastern China. Stable carbon isotopes and needle carbon and nitrogen status indicated lower levels of $\mathrm{N}$ and mobile carbohydrates in Pinus koraiensis trees, giving rise for concern how future climates may alter the competitive strength of the species and challenging ecosystem functioning and forest carbon sequestration.

It is of great interest to note that the variety of dendroecological topics which has strongly focused on climatic issues so far is increasingly broadened by basic ecological studies on the one hand and by more applied studies on the other hand. Liang et al. investigate climategrowth relationships of riverine poplar stands at the southern margin of the Qaidam Basin, an area with less than $500 \mathrm{~mm}$ of annual rainfall. Surprisingly, the trees respond positively to higher spring to early summer temperatures which seems contra-intuitional. However, warmer spring temperatures may lead to enhanced river discharge due to increased glacier meltwater production and thus to improved water supply of groundwaterdependent trees growing in a desert environment. By applying cell size analyses on root systems of spruce trees on degraded slopes, Zhou et al. are able to derive estimates of erosion rates caused by human impact in forest ecosystems at the northern part of the Tibetan plateau. Stable carbon isotope variations and changes in the intrinsic water-use efficiency of Tibetan junipers are reported by Xu et al. The long-term trend of decreasing $\delta^{13} \mathrm{C}$ since 1850 is attributed to fossil fuel combustion since the industrial revolution is strongly enhanced after 1975 , pointing to an interference of global environmental change processes with regional changes in the hydrological system.

Finally, two articles are dedicated to the tropical part of Asia. In a review paper, Pumijumnong provides an overview of the development of tree-ring research in South Asia, where for many years work on teak has been very prominent and pioneering for tropical dendrochronology in general. Recent studies, however, have successfully laid the basis for dendroecological studies on other tropical tree species, growing in perhumid tropical rainforest environments, in seasonal monsoon forests, or in mangrove forests, applying newly developed techniques of stable isotope analyses and quantitative wood anatomy. This is exemplified by a study on cambial phenology of trees from an evergreen seasonal rainforest in Thailand.

We hope that the spectrum of articles presented in this special issue of TREES is of interest for ecologists dealing with trees in general and reflects current trends in Asian dendroecological research in particular. 